SCIENTIFIC LETTER

\title{
Use of 3 French catheters for diagnostic and interventional procedures in newborns and small infants
}

\author{
G Agnoletti, Y Boudjemline, E Largen, Y Aggoun, I Szezepanski, D Bonnet, D Sidi
}

Heart 2003;89:1350-1351

$\Lambda$ a result of advances in cardiac surgery and interventional treatment, cardiac catheterisation is now being performed more often in neonates and small infants. In these patients the vascular approach is a major concern because of limited vascular access and the potential for vascular damage. ${ }^{12}$ For these reasons, the miniaturisation of diagnostic catheters and interventional tools to preserve vascular access in small patients is of vital importance.

The aim of our study was to assess the feasibility and safety of diagnostic and interventional procedures performed in small infants using 3 French sheaths and catheters, and to evaluate their results.

\section{PATIENTS AND METHODS}

From January 2001 to December 2002 we performed 11 diagnostic and five interventional procedures in 15 infants, utilising 3 French sheaths and catheters. Inclusion criteria were: need for arterial catheterisation in patient weighing $\leqslant 4 \mathrm{~kg}$, or need for venous catheterisation in patient $<3 \mathrm{~kg}$. The median age and weight of the patients were 7 days (range 1-180 days) and $2.8 \mathrm{~kg}$ (range $2-4 \mathrm{~kg}$ ), respectively. Diagnosis and type of procedure are listed in table 1.

IVA valve sheaths (Balt, Montmorency, France) are made of high density polyethylene and have a low coefficient of friction. The sheath is adjusted on the dilator for a nontraumatic use. It is supplied with a guide of 0.018 inch diameter. Introduction over the wire does not need skin incision.

The custom made 3 French angiography catheters (Balt, Montmorency, France) are made of polyamide. This material has high pressure tolerance and low pliability. Diagnostic catheters used were NIH, pig tail, and Judkins right, and were each $50 \mathrm{~cm}$ in length. The distal end of the pig tail was modified in order to have distal, close holes and a tail measuring $5 \mathrm{~mm}$ in diameter. For interventional procedures we utilised the mini Ty Shak balloon (Numed Inc, Hopkinton, New York, USA).

The pressure/output relation of the 3 French catheters were tested in vitro utilising the same contrast medium employed in vivo (Ultravist) and a Medrad Mark V injector.

Diagnostic and interventional catheterisations were performed using standard techniques, utilising a Judkins right catheter for right diagnostic catheterisation and an NIH or pig tail catheter for left catheterisation.

All patients underwent ultrasound evaluation of femoral vessels at a median follow up of 77 days (range 10-210 days). All ultrasound studies were performed with an Esaote Megas echograph. A 9.0 MHz transducer was placed approximately $1 \mathrm{~cm}$ below the inguinal ligament, medial to the pulsation of the femoral artery. Long and short axis images of the femoral artery and vein were obtained. The femoral arterial dimension was measured at its point of maximal expansion between the endothelial lines. The diameter was expressed as a ratio: cannulated versus non-cannulated vessel. Doppler interrogation was performed at multiple sites along the femoral artery. Data for each patient comprised the mean of five consecutive measurements.

\section{RESULTS}

Diagnostic catheterisation obtained the required information in all cases. Following the results of an in vitro test, injection of 4-6 ml over one second at 300 and 800 Psi, respectively, resulted in good visualisation of the ventricular cavities and/ or large vessels. Blood sampling was possible by using gentle aspiration. Pressure measurement enabled the evaluation of peak to peak gradient through right and left ventricular outflow. When required, it was always possible to perform an interventional procedure. Selective coronary angiography was also possible.

No complications were observed.

The price of a diagnostic or interventional procedure performed with a 3 French sheath and catheter cost $€ 23$ (£16) more than a procedure using material measuring 4 French or more.

At follow up all the vessels of the examined patients were patent, without stenosis or collateral circulation.

\section{DISCUSSION}

Development in interventional catheterisation and cardiac surgery has led to early treatment of most congenital heart diseases. Progressive miniaturisation of diagnostic and interventional tools has enabled diagnostic and interventional procedures to be undertaken in neonates and infants. However, vascular complications after cardiac catheterisation or cardiac surgery are still frequent. ${ }^{3}$ The incidence of arterial occlusion after neonatal femoral catheterisation varies between $30-45 \%^{13}$; thus, in neonates, interventional catheterisation through an arterial approach is not advised. Limitation of sheath size is of major concern in infants weighing less than $3 \mathrm{~kg}$, because of limited vascular access. A high incidence of femoral occlusion has been demonstrated in low weight neonates undergoing arterial catheterisation. ${ }^{2}$ Preservation of femoral vascular access is mandatory in order to avoid a possible impaired limb growth ${ }^{4}$ and allow future catheterisations. It has been show that the size of a normal femoral vein and femoral artery in neonates does not exceed $1.5 \mathrm{~mm} .^{5}$ Commercial sheaths are usually defined in accordance with their internal lumen. Thus, a 4 French sheath allows the introduction of a 4 French catheter, but its external lumen measures $2 \mathrm{~mm}$, with minor variations for different products. It follows that a 4 French sheath completely occludes the lumen of a normal femoral artery or vein of a neonate.

Our results show that diagnostic and interventional investigations can be performed in newborns utilising 3 French sheaths and catheters without any acute complication.

The major advantage related to the use of this material concerns the ratio of external sheath lumen to diameter of the femoral vessel. Even if still close to 1, this improved ratio 
Table 1 Patient characteristics and haemodynamic procedures

\begin{tabular}{|c|c|c|c|c|c|c|c|c|}
\hline $\mathrm{n}$ & Diagnosis & Days & $\begin{array}{l}\text { Weight } \\
(\mathrm{kg})\end{array}$ & $\begin{array}{l}\text { Vascular } \\
\text { access }\end{array}$ & $\begin{array}{l}\text { Pressure } \\
\text { measurement }\end{array}$ & $\begin{array}{l}\text { Blood } \\
\text { sampling }\end{array}$ & Angiography & Interventional procedure \\
\hline 1 & Shone syndrome & 1 & 2.5 & FA & Yes & Yes & Aorta & Aortic isthmus dilation \\
\hline 2 & TA, PA, discontinuous Pas & 5 & 2 & FA & No & Yes & $\mathrm{LV}$, aorta & No \\
\hline 3 & $\begin{array}{l}\text { Tetralogy of Fallot + azygos } \\
\text { continuation }\end{array}$ & 21 & 2.4 & $(\mathrm{FV}), \mathrm{FA}$ & No & Yes & LV and RV & No \\
\hline 4 & Tetralogy of Fallot & 11 & 2.8 & FA & No & Yes & $L V, R V$, coronary arteries & No \\
\hline 5 & Aorto-pulmonary window & 180 & 4 & FA & No & Yes & Aorta, coronary arteries & No \\
\hline 6 & Tetralogy of Fallot & 60 & 3.8 & FA & No & Yes & $\mathrm{LV}, \mathrm{RV}$, coronary arteries & No \\
\hline 7 & Single ventricle + PA & 1 & 3 & FA & No & Yes & LV, aorta & No \\
\hline 8 & Pulmonary atresia + VSD & 7 & 3 & FA & No & Yes & $\mathrm{LV}$, aorta & No \\
\hline 9 & Tetralogy of Fallot & 8 & 2.7 & FA & No & Yes & LV, RV, coronary arteries & No \\
\hline 10 & VSD with $\mathrm{PH}$ & 45 & 4 & (FV), FA & Yes & Yes & LV & No \\
\hline 11 & Pulmonary stenosis & 9 & 2.4 & $\mathrm{FV}$ & Yes & Yes & RV & Pulmonary valve dilation \\
\hline 12 & Shone syndrome & 3 & 2.7 & FA & Yes & Yes & Aorta & $\begin{array}{l}\text { Aortic valve and aortic } \\
\text { isthmus dilation }\end{array}$ \\
\hline 13 & Aortic stenosis & 3 & 3 & FA & Yes & Yes & Aorta & Aortic valve dilation \\
\hline 14 & Pulmonary atresia + VSD & 180 & 2.8 & FA & No & Yes & Aorta, MAPCAs & No \\
\hline 15 & Interrupted aortic arch & 6 & 3.2 & $(\mathrm{FV}), \mathrm{FA}$ & No & Yes & Aorta & No \\
\hline
\end{tabular}

FA, femoral artery; FV, femoral vein; (FV), femoral vein when cannulated with a 4 French sheath; LV, left ventricle; MAPCAs: major aorto-pulmonary collateral arteries; PA, pulmonary atresia; Pas, pulmonary arteries; PH, pulmonary hypertension; RV, right ventricle; TA, tricuspid atresia; VSD, ventricular septal defect.

should allow limb perfusion during catheterisation and reduce wall trauma.

Echocardiographic results are encouraging and should allow the indications for arterial catheterisation in newborns to be extended, and, in particular, should authorise the retrograde approach for treatment of aortic stenosis and coarctation.

Arterial interventional catheterisation through 3 French sheaths could also be advisable after the neonatal period.

The financial implications of using 3 French material are not a major concern, and should be minimised by a more extensive use of this material.

However, the concern raised over the quality of angiography and pressure measurements obtained through 3 French catheters could limit their use to procedures that do not require an angiographic diagnosis. It is possible that further improvements in radiation technology could abolish the need for rapid high volume injections to obtain high quality images. In addition, the possibility of reliable pressure measurement through a small lumen catheter is under development.

\section{Authors' affiliations}

G Agnoletti, Y Boudjemline, Y Aggoun, I Szezepanski, D Bonnet, D Sidi, Service de Cardiologie Pédiatrique, Necker Enfants Malades, Paris, France
E Largen, Balt, Montmorency, France

Correspondence to: Dr Gabriella Agnoletti, Service de Cardiologie Pédiatrique, Groupe Hospitalier Necker Enfants Malades, 149, rue de Sèvres, 75743 Paris, France; gabriella.agnoletti@nck. ap-hop-paris. fr

Accepted 10 June 2003

\section{REFERENCES}

1 Burrows PE, Benson LN, Williams WG, et al. lliofemoral arterial complications of balloon angioplasty for systemic obstruction in infants and children. Circulation 1990;82:1697-704.

2 Kretschmar O, Dahnert I, Berger F, et al. Interventional treatment of congenital heart defects in infants with a body weight up to 2.500 grams. Z Kardiol 2000;89:1 126-32.

3 Burrows PE, Benson LN, Babyn P, et al. Magnetic resonance imaging of the iliofemoral arteries after balloon dilation angioplasty of aortic arch obstructions in children. Circulation 1994;90:915-20.

4 Ing FF, Faghan TE, Grifka RG, et al. Reconstruction of stenotic or occluded iliofemoral veins and vena cava using intravascular stents: re-establishing access cardiac catheterization and cardiac surgery. J Am Coll Cardiol 2001;37:251-7.

5 Akingbola OA, Nielsen J, Hopkins RL, et al. Femoral vein size in newborns and infants: preliminary investigation. Crit Care 2000;4:120-3.

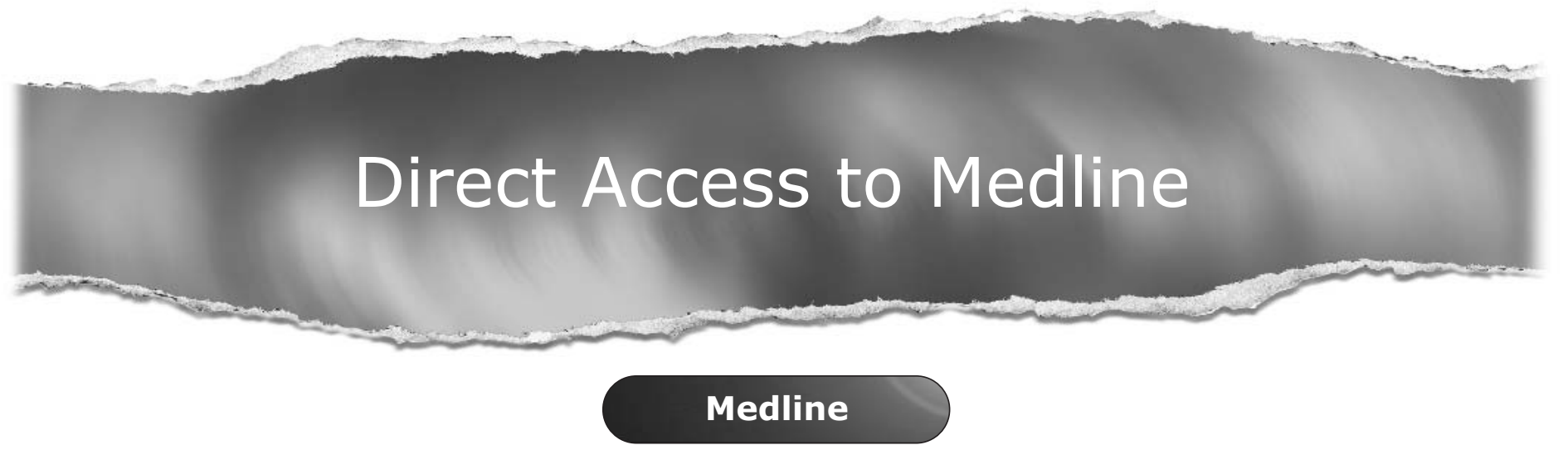

Link to Medline from the homepage and get straight into the National Library of Medicine's premier bibliographic database. Medline allows you to search across 9 million records of bibliographic citations and author abstracts from approximately 3,900 current biomedical journals. 